\title{
Effect of ARID1A mutation and expression on prognosis of hepatocellular carcinoma and cholangiocarcinoma: a meta-analysis
}

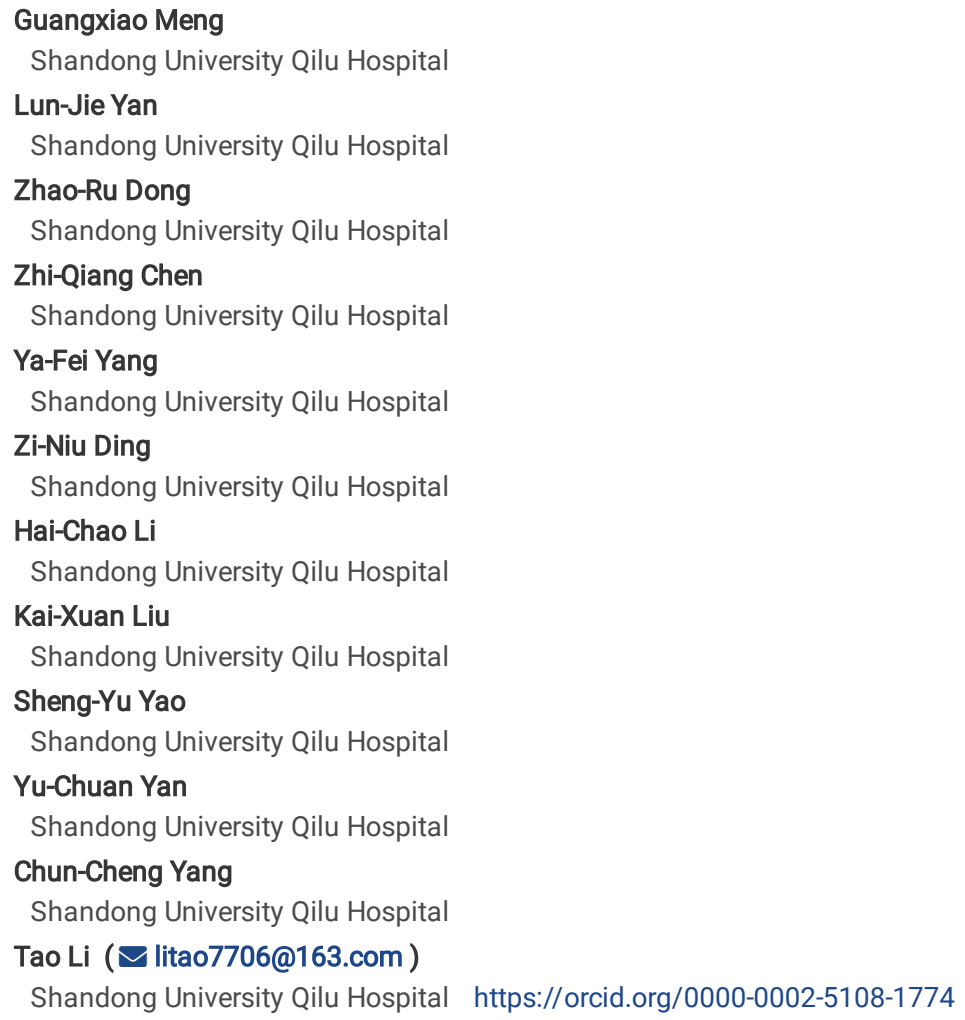




\section{Abstract}

Background: Hepatocellular carcinoma (HCC) and cholangiocarcinoma are the most common liver malignant tumors worldwide. Investigating the molecular basis of these malignancies is vital to the development of new treatments. Recent studies have found that mutation and abnormal expression of ARID1A, are frequently shown in HCC and cholangiocarcinoma. Herein, we aimed to estimate the effects of ARID1A mutation and expression on prognosis of HCC and cholangiocarcinoma.

Methods: We searched PubMed, EMBASE, Web of Science, the Cochrane Library for studies evaluating the relationship between ARID1A mutations or expression and the survival of HCC or cholangiocarcinoma patients. Meta-analysis was performed to generate a combined $H R$ with a $95 \%$ confidence interval (Cl) for overall survival (OS).

Results: We identified 12 articles that evaluated the impact of ARID1A mutation or expression on the prognosis of patients with HCC or cholangiocarcinoma. Six studies provided data on HCC survival and 6 studies examined cholangiocarcinoma survival. For HCC, ARID1A mutation carriers or patients with low ARID1A expression had worse OS $(H R=1.75 ; 95 \% C l=1.22-2.51)$ than non-carriers or patients with high ARID1A expression. For cholangiocarcinoma, ARID1A mutation carriers or patients with low ARID1A expression also had significantly shorter OS $(H R=3.70,95 \% \mathrm{Cl}=2.88-4.76)$.

Conclusions: Our study suggests that ARIDIA mutation or low expression is strongly associated with poor prognosis of patients with HCC or cholangiocarcinoma, and may be considered as a potential prognostic biomarker for these patients.

\section{Background}

Liver cancer is one of the most common malignancies in the world and the fourth leading cause of cancer death[1,2]. Cholangiocarcinoma, also known as bile duct cancer, originating from the biliary epithelium, is a group of heterogeneous malignant tumors with poor prognosis which ranked the second most common cancer of the liver and gallbladder worldwide[3].

ATP-dependent chromatin remodelers utilize the energy of ATP to regulate DNA transcription[4]. Next-generation gene sequencing shows that subunits of the SWI/SNF complex, encoding the ATP-dependent chromatin remodelers, are frequently mutated in a wide variety of cancers, such as lung cancer[5], rhabdoid tumors, gastric adenocarcinoma, malignant melanoma[6]. ARID1A mutations are frequently shown in SWI/SNF genes. Previous study had demonstrated that repeated mutation of ARID1A related to the development of many types of cancer. Most ARID1A mutations are inactivated mutations that lead to loss of ARID1A expression[7]. Thus, ARID1A was considered as a broad tumor suppressor[8]. Mutations and abnormal expression of ARID1A have been found in a variety of cancers, such as urothelial bladder tumors[9], colorectal cancer[10], nonfunctional pancreatic neuroendocrine tumors[11], invasive micropapillary carcinomas of the breast[12], endometriosis and uterine endometrioid carcinoma[13, 14].

ARID1A has a relatively high mutation frequency in both HCC (6.9\%-17\%)[15-17] and biliary tract cancers(12.1\%-33\%)[18-20]. Hu, Chaobo et al. reported that ARID1A deficiency occurred in advanced human HCC and promoted HCC progression[21]. A large amount of studies have manifested that patients of HCC or cholangiocarcinoma with ARID1A mutation or low expression had shorter OS than those of noncarriers or patients with high ARID1A expression[17, 22-25]. However, inconsistent conclusions were demonstrated that ARID1A mutation or expression has no significant influence on OS[26-28]. In HCC, Zhao, Jie et al. reported that $87.8 \%$ tumors ARID1A mRNA and BAF250a protein expression levels were increased compared with adjacent noncancerous tissues[27]. Animal experiment showed that ARID1A had both oncogenic and tumor suppressor functions in liver cancer[29]. Therefore, to further understand the association between ARID1A and liver cancer, we perform a meta-analysis to assess the effectiveness of ARID1A mutation and expression on the prognosis of HCC and cholangiocarcinoma.

\section{Methods}

This meta-analysis followed the preferred reporting items for systematic reviews and meta-analyses: the PRISMA statement[30].

\section{Literature search}

All relevant studies were selected from PubMed, Embase, Web of Science and Cochrane Library from the inception of the databases through July $15,2020$. Searching terms included subject terms("ARID1A") AND ("hepatocellular carcinoma" OR "cholangiocarcinoma") and their related entry terms. We also retrieved the references of the included publications and related reviews manually.

\section{Eligibility Criteria}

The selection criteria of this study were: (a) patients recruited with proven HCC or cholangiocarcinoma according to histological results; (b) investigated the association between ARID1A mutation or expression and prognosis of HCC or cholangiocarcinoma; (c) reported the hazard ratio or $95 \%$ confidence interval or provided data for calculation. We excluded the studies as follow: (a) non-English paper; (b) animal or in vitro experiments; (c) review articles, case reports, editorials, letters, commentaries; (d) not HCC or cholangiocarcinoma; (e) studies without liver cancer overall survival data or without sufficient data or KaplanMeier plots to calculate risk.

\section{Study Selection And Data Extraction}

Two investigators (G.-X. M. and L.-J. Y.) performed a preliminary screening on titles and abstracts of all retrieved literatures independently. Then, full texts were reviewed for eligibility. When two investigators had different opinions, disagreements were resolved by thorough discussion with another reviewer (Z.-R.D.). We extracted the following information from each article: authors' information, year of publication, country, test methods, number of patients (altered and non-

Page $2 / 9$ 
altered), follow-up period, endpoints (OS) and clinical features of HCC patients included sex, cirrhosis, tumor size, histological differentiation, HBV infection. If $H R$ and $95 \% \mathrm{Cl}$ were not provided, Get Data software was used to extract the survival information from the Kaplan-Meier curve.

\section{Quality Assessment}

The quality of each article was independently assessed by two investigators (G.-X. M. and L.-J. Y.) according to the Newcastle-Ottawa Scale (NOS). Each article can be rated with a maximum of 9 points: selection has 4 , comparability has 2 and outcome has 3 .

\section{Statistical analysis}

We extracted any reported relative risks (RRs), hazard ratios (HRs), odds ratios (ORs) with $95 \%$ confidence interval $(C l)$ for $O S$. When adjusted and unadjusted effect sizes were both available, priority was given to the former one. The heterogeneity between the groups was examined by $Q$ test. $P>50 \%$ accompanied with $p$ value $<0.1$ was considered as a cutoff for statistically significant heterogeneity. The fixed-effects model was initially used to obtain the aggregated $H R s$ and $95 \% \mathrm{Cl}$, and if substantial heterogeneity existed, the aggregated $H R$ s were estimated using random-effects models. The publication bias was assessed through visually inspecting the symmetry of the funnel plot and evaluated with Begg's funnel plot and Egger's test. Sensitivity analysis is used to detect the stability of the results. This meta-analysis was performed using the STATA 12.0 software (Stata Corporation, College Station, TX, USA).

\section{Results}

\section{Study selection}

We retrieved 563 papers according to search strategy. There left 384 articles after the exclusion of duplicates. Finally, 12 articles meeting the eligibility criteria were included in this study. One of them was a meeting abstract. Figure 1 summarizes the process of literature screening. The average NOS score of these studies was 8.5(Additional file 1: Supplementary Table 1), which indicated that included studies were of relatively high quality.

\section{Study characteristics}

The meta-analysis for HCC included six studies. The characteristics of the patient cohort are shown in Table 1. The relationship between the clinical characteristics of HCC patients and the expression level of ARID1A is shown in Table 2. The studies published between 2015 and 2020 . A total of 950 patients were assimilated into our study including 195 patients with ARID1A mutation or low expression, and 755 patients with no ARID1A mutation or high expression. Two studies focused on ARID1A gene mutations[16, 17], and four focused on ARID1A expression[22, 26, 27, 31]. In these studies, the most used methods to detect mutations and expression of ARID1A were PCR, next-generation sequencing, and immunohistochemistry.

Table 1

Baseline characteristics of hepatocellular carcinoma included in the studies.

\begin{tabular}{|c|c|c|c|c|c|c|c|c|c|c|}
\hline \multirow{3}{*}{ Author(ref.) year } & \multirow{3}{*}{ Country } & \multirow{3}{*}{ Methods } & \multicolumn{8}{|c|}{ ARID1A(number) } \\
\hline & & & ALL & Altered & Normal & Median/range & Hazard & $95 \%$ & $\mathrm{p}-$ & Altered \\
\hline & & & & & & $\begin{array}{l}\text { Of follow-up, } \\
\mathrm{m}\end{array}$ & & & & \\
\hline $\begin{array}{l}\text { Abe, } \\
\text { Hiroyuki[26]2015 }\end{array}$ & Japan & immunohistochemistry & 290 & 63 & 227 & NA & 1.08 & $\begin{array}{l}0.80- \\
1.45\end{array}$ & 0.99 & expression \\
\hline He, Fei[22]2015 & China & $\begin{array}{l}\mathrm{PCR}[\text { western blotting } \\
\text { immunohistochemistry }\end{array}$ & 64 & 41 & 23 & NA & 2.12 & $\begin{array}{l}1.14- \\
3.94\end{array}$ & 0.042 & expression \\
\hline Kelly, L[16]2020 & US & $\begin{array}{l}\text { institutional multigene } \\
\text { assay }\end{array}$ & 64 & 11 & 53 & NA & 2.12 & $\begin{array}{l}1.01- \\
4.43\end{array}$ & 0.046 & gene \\
\hline Li, Li[17]2020 & China & Next-generation sequencing & 362 & 25 & 337 & NA & 2.577 & $\begin{array}{l}1.42- \\
4.675\end{array}$ & 0.0372 & gene \\
\hline Zhao, Jie[27]2016 & China & PCR immunohistochemistry & 115 & 14 & 101 & $38(3-72)$ & 1.19 & $\begin{array}{l}0.58- \\
2.43\end{array}$ & 0.612 & expression \\
\hline $\begin{array}{l}\text { Zhou, } \\
\text { Dingzhong[32]2019 }\end{array}$ & China & immunohistochemistry & 60 & 41 & 19 & NA & 2.31 & $\begin{array}{l}1.36- \\
3.92\end{array}$ & 0.021 & expression \\
\hline
\end{tabular}


Table 2

The relationship between the clinical characteristics of HCC patients and the expression level of ARID1A.

\begin{tabular}{|c|c|c|c|c|c|c|c|c|c|c|c|c|c|c|c|c|}
\hline \multirow[t]{3}{*}{ Author(ref.) year } & \multicolumn{4}{|l|}{ Sex } & \multicolumn{4}{|c|}{ Cirrhosis } & \multicolumn{4}{|c|}{ Tumor size } & \multicolumn{4}{|c|}{ Histological differentiation } \\
\hline & \multicolumn{4}{|c|}{ ARID1A expression } & \multicolumn{4}{|c|}{ ARID1A expression } & \multicolumn{4}{|c|}{ ARID1A expression } & \multicolumn{4}{|c|}{ ARID1A expression } \\
\hline & & high & low & $\begin{array}{l}P \\
\text { value }\end{array}$ & & high & low & $\begin{array}{l}\mathrm{P} \\
\text { value }\end{array}$ & & high & low & $\begin{array}{l}\mathrm{P} \\
\text { value }\end{array}$ & & high & low & $\begin{array}{l}\mathrm{P} \\
\text { value }\end{array}$ \\
\hline \multirow{3}{*}{$\begin{array}{l}\text { Abe, Hiroyuki } \\
{[26] 2015}\end{array}$} & Male & 180 & 49 & \multirow[t]{3}{*}{0.79} & Present & 127 & 38 & \multirow[t]{3}{*}{0.54} & \multirow{3}{*}{$\begin{array}{l}\leq \\
5 \mathrm{~cm}\end{array}$} & 168 & 38 & \multirow[t]{3}{*}{0.034} & Well & 69 & 23 & \multirow[t]{3}{*}{0.035} \\
\hline & \multirow[t]{2}{*}{ Female } & \multirow[t]{2}{*}{47} & \multirow[t]{2}{*}{14} & & \multirow[t]{2}{*}{ Absent } & \multirow[t]{2}{*}{100} & \multirow[t]{2}{*}{25} & & & \multirow[t]{2}{*}{59} & \multirow[t]{2}{*}{25} & & Mod & 123 & 38 & \\
\hline & & & & & & & & & & & & & Poor & 35 & 2 & \\
\hline \multirow[t]{3}{*}{ He, Fei [22]2015 } & Male & 10 & 6 & \multirow[t]{3}{*}{0.554} & Present & 14 & 9 & \multirow[t]{3}{*}{0.396} & \multirow{3}{*}{$\begin{array}{l}\leq \\
5 \mathrm{~cm} \\
\otimes 5 \mathrm{~cm}\end{array}$} & 20 & 14 & \multirow[t]{3}{*}{0.252} & Well- & 33 & 19 & \multirow[t]{3}{*}{0.557} \\
\hline & Female & 31 & 17 & & Absent & 27 & 14 & & & 21 & 9 & & Mod & 8 & 4 & \\
\hline & & & & & & & & & & & & & Poor & & & \\
\hline \multirow[t]{2}{*}{ Zhao, Jie [27]2016 } & Male & 81 & 13 & \multirow[t]{2}{*}{0.460} & Present & 66 & 8 & \multirow[t]{2}{*}{0.563} & \multirow{2}{*}{$\begin{array}{l}\leq \\
5 \mathrm{~cm} \\
\otimes 5 \mathrm{~cm}\end{array}$} & 81 & 6 & \multirow[t]{2}{*}{0.005} & NA & NA & NA & NA \\
\hline & Female & 20 & 1 & & Absent & 35 & 6 & & & 20 & 8 & & & & & \\
\hline Zhou, & Male & 17 & 26 & 0.907 & Present & 18 & 23 & 0.365 & $\leq$ & 18 & 16 & 0.019 & Well- & 12 & 11 & 0.688 \\
\hline & Female & 7 & 10 & & Absent & 6 & 13 & & & 6 & 20 & & Mod & 8 & 9 & \\
\hline & & & & & & & & & & & & & Poor & 4 & 7 & \\
\hline
\end{tabular}

The meta-analysis for cholangiocarcinoma included six studies. The characteristics of the patient cohort are shown in Table 3 . The studies published between 2016 and 2020. We included 620 patients composed of 70 patients with ARID1A mutation or low expression and 550 patients with no ARID1A mutation or high expression. Four studies focused on ARID1A gene mutations[23, 24, 28, 32], and two focused on ARID1A expression[25, 33]. In these studies, the most used methods to detect mutations and expression of ARID1A were generation sequencing, PCR, western blotting, and immunohistochemistry.

Table 3

Baseline characteristics of cholangiocarcinoma included in the studies.

\begin{tabular}{|c|c|c|c|c|c|c|c|c|c|c|}
\hline \multirow[b]{2}{*}{ Author(ref.) year } & \multirow[b]{2}{*}{ Country } & \multirow[b]{2}{*}{ Methods } & \multicolumn{8}{|c|}{ ARID1A(number) } \\
\hline & & & ALL & Altered & Normal & $\begin{array}{l}\text { Median/range } \\
\text { Of follow-up, } \\
\mathrm{m}\end{array}$ & $\begin{array}{l}\text { Hazard } \\
\text { ratio }\end{array}$ & $95 \% \mathrm{Cl}$ & $\begin{array}{l}\mathrm{p}- \\
\text { value }\end{array}$ & Altered \\
\hline $\begin{array}{l}\text { Ruzzenente, A } \\
\text { [23]2016 }\end{array}$ & NA & generation sequencing & 18 & 2 & 16 & $28.3 \pm 25.8$ & 5.337 & $\begin{array}{l}1.325- \\
21.489\end{array}$ & 0.018 & gene \\
\hline $\begin{array}{l}\text { Sasaki, Motoko } \\
{[28] 2016}\end{array}$ & Japan & generation sequencing & 53 & 6 & 47 & 21 & 1.15 & $\begin{array}{l}0.46- \\
2.88\end{array}$ & 0.98 & gene \\
\hline $\begin{array}{l}\text { Simbolo, Michele } \\
\text { [33]2018 }\end{array}$ & Italy & generation sequencing & 66 & 6 & 60 & $\begin{array}{l}40.7(2.0- \\
152.7)\end{array}$ & 6.9059 & $\begin{array}{l}2.271- \\
21.008\end{array}$ & 0.0007 & gene \\
\hline $\begin{array}{l}\text { Wardell, Christopher P } \\
\text { [24] } 2018\end{array}$ & $\begin{array}{l}\text { Japan } \\
\text { Italy }\end{array}$ & generation sequencing & 357 & 22 & 335 & 24 & 4.13 & $\begin{array}{l}3.05- \\
5.60\end{array}$ & 0.025 & gene \\
\hline Yang, S. Z [34]2016 & China & PCR $\llbracket$ western blotting & 57 & 19 & 38 & NA & 3.967 & $\begin{array}{l}1.299- \\
12.118\end{array}$ & 0.016 & expression \\
\hline Yoshino, J[25]2020 & Japan & $\begin{array}{l}\text { Immunohistochemistry } \\
\text { western blotting } \mathrm{PCR}\end{array}$ & 69 & 15 & 54 & NA & 2.73 & $\begin{array}{l}1.29- \\
5.78\end{array}$ & 0.008 & expression \\
\hline
\end{tabular}

\section{Prognostic value of ARID1A mutations and expression for HCC and cholangiocarcinoma}

\subsection{HCC prognosis}

Six studies were conducted on the effect of ARID1A mutations and expression on the OS of HCC. In this OS meta-analysis, patients with ARID1A mutation or low expression had worse OS, with a combined $H R$ of $1.75\left(95 \% C l, 1.12-2.51\right.$, Fig. 2). Because of the substantial heterogeneity $\left(I^{2}=61 \%, p=0.025\right)$, the random-effects model was used. Due to different states of altered ARID1A, six articles were divided into two groups. Two articles focused on the effect of ARID1A gene mutation on OS of HCC, combined $H R$ was $2.39(95 \% C l, 1.50-3.79)$. Heterogeneity was not found in two studies $\left(I^{2}=0 \%, p=0.687\right)$. Four articles focused on the effect of ARID1A expression on OS of HCC, combined $H R$ was $1.51(95 \% C l, 1.01-2.37)$. Significant heterogeneity was found in four 
studies $\left(I^{2}=63.6 \%, p=0.041\right)$. Besides, the results showed that the expression of ARID1A in HCC was not related to sex, cirrhosis, histological differentiation, or HBV infection, but was negatively correlated with tumor size $(R R=1.53,95 \% C l, 1.18-1.99$; Additional file 2: Supplementary Fig. 1).

\subsection{Cholangiocarcinoma prognosis}

Six studies were conducted on the effect of ARID1A mutations and expression on the OS of cholangiocarcinoma. Patients with ARID1A mutation or low expression had a significantly shorter OS, with a combined $H R$ of 3.70 (95\% Cl, 2.88-4.76; Fig. 2). On account of slight heterogeneity without statistical significance $\left(I^{2}=43.6 \%, p=0.115\right)$, the fixed effect model was used for analysis. Due to different states of altered ARID1A, six articles were divided into two groups. Four articles focused on the effect of ARID1A gene mutation on OS of cholangiocarcinoma, combined $\mathrm{HR}$ was 3.84 (95\% $\mathrm{Cl}$, 2.92-5.05). Significant heterogeneity was found $\left(I^{2}=63.2 \%, p=0.043\right)$. Two articles focused on the effect of ARID1A expression on OS of cholangiocarcinoma and combined $H R$ was $3.07(95 \% C l, 1.65-5.71)$. Heterogeneity was not found $\left(I^{2}=0 \%, p=0.586\right)$.

\section{Publication bias analysis}

Slight publication bias was detected by the Egger's test in HCC studies, but there was no publication bias according to Begg's test in this meta-analysis (Fig. 3).

\section{Sensitivity analysis}

To understand how each study on the influence of this meta-analysis, we conducted a sensitivity analysis. The result showed that no studies that have an impact on the pooled HR (Fig. 4). This confirmed the robustness of the meta-analysis.

\section{Discussion}

In our study, we estimated the effects of ARID1A mutation and expression on the prognosis of HCC and cholangiocarcinoma. The results showed that both HCC and cholangiocarcinoma patients with ARID1A mutation or low expression had significantly shorter OS. Our findings suggest that ARID1A may be considered as a potential prognostic biomarker for HCC and cholangiocarcinoma patients.

Genome sequencing finds there are many common mutated genes in HCC and cholangiocarcinoma, such as TP53, CTNNB1, ARID1A[15, 17-19]. ARID1A is considered to be a broad tumor suppressor. However, the exact mechanism by which ARID1A abnormality leads to increased risk of HCC and cholangiocarcinoma and decreases overall survival remains largely unknown. Existing studies suggest that subunits of the SWI/SNF complex, encoding the ATP-dependent chromatin remodelers, are frequently mutated in a wide variety of cancers and ARID1A mutations are frequently shown in SWI/SNF genes. Most ARID1A mutations are inactivated mutations, resulting in the loss of ARID1A expression[7]. Because of the absence of ARID1A, abnormal SWI/SNF complex leads to a defect in enhancer activity, which impairs differentiation programs and causes widespread dysregulation of gene expression, thus promoting tumor formation[34]. Furthermore, mutations and deletions of ARID1A contribute to the proliferation and migration of HCC[29, 35], and this situation also exists in the cholangiocarcinoma[25], which may lead to poor prognosis of patients suffering from HCC and cholangiocarcinoma. It is worth noting that the inactivation of ARID1A is significantly correlated with the activation of the PI3K/mTOR pathway, which is considered as a carcinogenic pathway by virtue of its role in cell proliferation and cell cycle control [36, 37]. This is consistent with our findings.

Our meta-analysis also integrated the clinicopathologic features of HCC patients. The results showed that expression of ARID1A was not related to sex, cirrhosis, histological differentiation, or HBV infection. However, low ARID1A expression in HCC was associated with tumor size. This further indicated that the low expression of ARID1A promoted cancer proliferation. Since only four studies included these clinical features, it is necessary to conduct more accurate detection of ARID1A expression and clinicopathological features in the future.

This study also has some limitations that cannot be neglected. Firstly, due to the number of included studies, there are not enough cases to adequately evaluate the relationship between ARID1A changes and OS with HCC and cholangiocarcinoma. Secondly, the included studies are retrospective cohort studies rather than randomized controlled studies (RCT), inevitable recall bias and selection bias still exist, which may lead to a less convincing conclusion. Owing to limited OS data, we only conducted a group of subgroup analyses. Finally, slight publication bias was detected by the egger's test in HCC studies, but there was no publication bias according to Begg's test, this may be caused by the low number of studies.

\section{Conclusions}

In summary, this meta-analysis provides evidence for the hypothesis that ARID1A mutation or low expression is associated with poor prognosis in patients with HCC or cholangiocarcinoma. Thus, ARID1A may be considered as a potential prognostic biomarker for HCC and cholangiocarcinoma patients. However, more detailed studies with more dependable data and larger sample sizes are needed to further clarify the prognostic role of ARID1A mutation and expression.

\section{List Of Abbreviations}

Hepatocellular carcinoma, HCC; AT-rich interactive domain 1A, ARID1A; Confidence interval, Cl; Overall survival, OS; Newcastle-Ottawa Scale, NOS.

\section{Declarations}

\section{Ethics approval and consent to participate}

Not applicable.

\section{Consent for publication}


Not applicable.

\section{Competing interests}

The authors declare that they have no competing interests.

\section{Funding}

This work was supported by the Taishan Scholars Program for Young Expert of Shandong Province (tsqn20161064) and the National Natural Science Foundation of China (81874178). The funders had no roles in the design of the study and collection, analysis, and interpretation of data and in writing the manuscript.

\section{Authors' contributions}

Study concept and design: TL, GXM, LJY; Search strategy: GXM, LJY; Selection criteria: ZQC, YFY, ZND; Study selection: GXM, LJY, ZRD; Data extraction: GXM, LJY, ZRD, SYY; Analyze the data: GXM, LJY, HCL, KXL; Quality Assessment: YCY, CCY. All authors read and approved the final manuscript.

\section{Acknowledgements}

Not applicable.

\section{References}

1. Akinyemiju T, Abera S, Ahmed M, Alam N, Alemayohu MA, Allen C, Al-Raddadi R, Alvis-Guzman N, Amoako Y, Artaman A et al: The Burden of Primary Liver Cancer and Underlying Etiologies From 1990 to 2015 at the Global, Regional, and National Level: Results From the Global Burden of Disease Study 2015. JAMA oncology 2017, 3(12):1683-1691.

2. Bray F, Ferlay J, Soerjomataram I, Siegel RL, Torre LA, Jemal A: Global cancer statistics 2018: GLOBOCAN estimates of incidence and mortality worldwide for 36 cancers in 185 countries. CA: a cancer journal for clinicians 2018, 68(6):394-424.

3. Patel T: Cholangiocarcinoma-controversies and challenges. Nature reviews Gastroenterology \& hepatology 2011, 8(4):189-200.

4. Clapier CR, Cairns BR: The biology of chromatin remodeling complexes. Annual review of biochemistry 2009, 78:273-304.

5. Lissanu Deribe Y, Sun Y, Terranova C, Khan F, Martinez-Ledesma J, Gay J, Gao G, Mullinax RA, Khor T, Feng N et al: Mutations in the SWI/SNF complex induce a targetable dependence on oxidative phosphorylation in lung cancer. Nat Med 2018, 24(7):1047-1057.

6. Oike T, Ogiwara H, Nakano T, Yokota J, Kohno T: Inactivating mutations in SWI/SNF chromatin remodeling genes in human cancer. Jpn J Clin Oncol 2013, 43(9):849-855.

7. Wu RC, Wang TL, Shih le M: The emerging roles of ARID1A in tumor suppression. Cancer biology \& therapy 2014, 15(6):655-664.

8. Wu JN, Roberts CWM: ARID1A mutations in cancer: Another epigenetic tumor suppressor? Cancer Discovery 2013, 3(1):35-43.

9. Balbas-Martinez C, Rodriguez-Pinilla M, Casanova A, Dominguez O, Pisano DG, Gomez G, Lloreta J, Lorente JA, Malats N, Real FX: ARID1A Alterations Are Associated with FGFR3-Wild Type, Poor-Prognosis, Urothelial Bladder Tumors. Plos One 2013, 8(5).

10. Cajuso T, Hanninen UA, Kondelin J, Gylfe AE, Tanskanen T, Katainen R, Pitkanen E, Ristolainen H, Kaasinen E, Taipale M et al: Exome sequencing reveals frequent inactivating mutations in ARID1A, ARID1B, ARID2 and ARID4A in microsatellite unstable colorectal cancer. International Journal of Cancer 2014, 135(3):611-623.

11. Han X, Chen W, Chen P, Zhou W, Rong Y, Lv Y, Li JA, Ji Y, Chen W, Lou W et al: Aberration of ARID1A Is Associated With the Tumorigenesis and Prognosis of Sporadic Nonfunctional Pancreatic Neuroendocrine Tumors. Pancreas 2020, 49(4):514-523.

12. Onder S, Fayda M, Karanlık H, Bayram A, Şen F, Cabioglu N, Tuzlalı S, Illhan R, Yavuz E: Loss of ARID1A expression is associated with poor prognosis in invasive micropapillary carcinomas of the breast: A clinicopathologic and immunohistochemical study with long-term survival analysis. Breast Journal 2017, 23(6):638-646.

13. Liu G, Xu P, Fu Z, Hua X, Liu X, Li W, Zhang M, Wu J, Wen J, Xu J et al: Prognostic and Clinicopathological Significance of ARID1A in Endometrium-Related Gynecological Cancers: A Meta-Analysis. Journal of Cellular Biochemistry 2017, 118(12):4517-4525.

14. Xie H, Chen P, Huang HW, Liu LP, Zhao F: Reactive oxygen species downregulate ARID1A expression via its promoter methylation during the pathogenesis of endometriosis. European Review for Medical and Pharmacological Sciences 2017, 21(20):4509-4515.

15. Howell J, Atkinson SR, Pinato DJ, Knapp S, Ward C, Minisini R, Burlone ME, Leutner M, Pirisi M, Buettner R et al: Identification of mutations in circulating cell-free tumour DNA as a biomarker in hepatocellular carcinoma. European Journal of Cancer 2019, 116:56-66.

16. Kelly L, Yarmohammadi H, Erinjeri J, Boas F, Petre E, Brown K, Brody L, Covey A, Getrajdman G, Solomon S et al: 4:03 PM Abstract No. 197 ARID1A mutations are associated with shorter time to local progression and worse overall survival after embolization of hepatocellular carcinomas. Journal of Vascular and Interventional Radiology 2020, 31(3):S90.

17. Li L, Rao X, Wen Z, Ding X, Wang X, Xu W, Meng C, Yi Y, Guan Y, Chen Y et al: Implications of driver genes associated with a high tumor mutation burden identified using next-generation sequencing on immunotherapy in hepatocellular carcinoma. Oncology Letters 2020, 19(4):2739-2748.

18. Chae H, Kim D, Yoo C, Kim KP, Jeong JH, Chang HM, Lee SS, Park DH, Song TJ, Hwang S et al: Therapeutic relevance of targeted sequencing in management of patients with advanced biliary tract cancer: DNA damage repair gene mutations as a predictive biomarker. European Journal of Cancer 2019, 120:31-39. 
19. Churi CR, Shroff R, Wang Y, Rashid A, Kang HC, Weatherly J, Zuo M, Zinner R, Hong D, Meric-Bernstam F et al: Mutation profiling in cholangiocarcinoma: Prognostic and therapeutic implications. PLoS ONE 2014, 9(12).

20. Hogdall D, Larsen OF, Linnemann D, Poulsen TS, Hogdall EV: Exome sequencing of 22 genes using tissue from patients with biliary tract cancer. Apmis 2020, 128(1):3-9.

21. Hu C, Li W, Tian F, Jiang K, Liu X, Cen J, He Q, Qiu Z, Kienast Y, Wang Z et al: Arid1a regulates response to anti-angiogenic therapy in advanced hepatocellular carcinoma. Journal of Hepatology 2018, 68(3):465-475.

22. He F, Li J, Xu J, Zhang S, Xu Y, Zhao W, Yin Z, Wang X: Decreased expression of ARID1A associates with poor prognosis and promotes metastases of hepatocellular carcinoma. Journal of Experimental \& Clinical Cancer Research 2015, 34.

23. Ruzzenente A, Fassan M, Conci S, Simbolo M, Lawlor RT, Pedrazzani C, Capelli P, D’Onofrio M, lacono C, Scarpa A et al: Cholangiocarcinoma Heterogeneity Revealed by Multigene Mutational Profiling: Clinical and Prognostic Relevance in Surgically Resected Patients. Annals of Surgical Oncology 2016, 23(5):1699-1707.

24. Wardell CP, Fujita M, Yamada T, Simbolo M, Fassan M, Karlic R, Polak P, Kim J, Hatanaka Y, Maejima K et al: Genomic characterization of biliary tract cancers identifies driver genes and predisposing mutations. Journal of Hepatology 2018, 68(5):959-969.

25. Yoshino J, Akiyama Y, Shimada S, Ogura T, Ogawa K, Ono H, Mitsunori Y, Ban D, Kudo A, Yamaoka S et al: Loss of ARID1A induces a stemness gene ALDH1A1 expression with histone acetylation in the malignant subtype of cholangiocarcinoma. Carcinogenesis 2020, 41(6):734-742.

26. Abe H, Hayashi A, Kunita A, Sakamoto Y, Hasegawa K, Shibahara J, Kokudo N, Fukayama M: Altered expression of AT-rich interactive domain 1A in hepatocellular carcinoma. International Journal of Clinical and Experimental Pathology 2015, 8(3):2763-2770.

27. Zhao J, Chen J, Lin H, Jin R, Liu J, Liu X, Meng N, Cai X: The Clinicopathologic Significance of BAF250a (ARID1A) Expression in Hepatocellular Carcinoma. Pathology \& Oncology Research 2016, 22(3):453-459.

28. Sasaki M, Nitta T, Sato Y, Nakanuma Y: Loss of ARID1A Expression Presents a Novel Pathway of Carcinogenesis in Biliary Carcinomas. American Journal of Clinical Pathology 2016, 145(6):815-825.

29. Sun X, Wang SC, Wei Y, Luo X, Jia Y, Li L, Gopal P, Zhu M, Nassour I, Chuang J-C et al: Arid1a Has Context-Dependent Oncogenic and Tumor Suppressor Functions in Liver Cancer. Cancer Cell 2017, 32(5):574-+.

30. Moher D, Liberati A, Tetzlaff J, Altman DG: Preferred reporting items for systematic reviews and meta-analyses: the PRISMA statement. PLoS medicine 2009, 6(7):e1000097.

31. Zhou D, Cao S, Long W, Luo L: EXPRESSION OF ARID1A IN HEPATOCELLULAR CARCINOMA AND ITS RELATION TO THE PROGNOSIS. Acta Medica Mediterranea 2019, 35(5):2411-2415.

32. Simbolo M, Vicentini C, Ruzzenente A, Brunelli M, Conci S, Fassan M, Mafficini A, Rusev B, Corbo V, Capelli P et al: Genetic alterations analysis in prognostic stratified groups identified TP53 and ARID1A as poor clinical performance markers in intrahepatic cholangiocarcinoma. Scientific Reports 2018, 8.

33. Yang SZ, Wang AQ, Du J, Wang JT, Yu WW, Liu Q, Wu YF, Chen SG: Low expression of ARID1A correlates with poor prognosis in intrahepatic cholangiocarcinoma. World Journal of Gastroenterology 2016, 22(25):5814-5821.

34. Mathur R: ARID1A loss in cancer: Towards a mechanistic understanding. Pharmacology and Therapeutics 2018, 190:15-23.

35. Cheng S, Wang L, Deng CH, Du SC, Han ZG: ARID1A represses hepatocellular carcinoma cell proliferation and migration through IncRNA MVIH. Biochem Biophys Res Commun 2017, 491(1):178-182.

36. Young YS, Shin JH, Jeong YS, Kang SH, Seo YS, Um SH, Lee JS: Loss of arid1a serves as prognostic biomarker for hepatocellular carcinoma and has synthetic lethality with pi3k/mtor inhibition. Hepatology 2018, 68:553A.

37. Pópulo H, Lopes JM, Soares P: The mTOR signalling pathway in human cancer. International journal of molecular sciences 2012, 13(2):1886-1918.

\section{Figures}


\begin{tabular}{l} 
Records identified through database \\
searching $(n=563)$ \\
Pubmed: 86 \\
Embase: 277 \\
Cochrane: 1 \\
Web of science: 199 \\
\hline
\end{tabular}
None of additional records identified through other sources

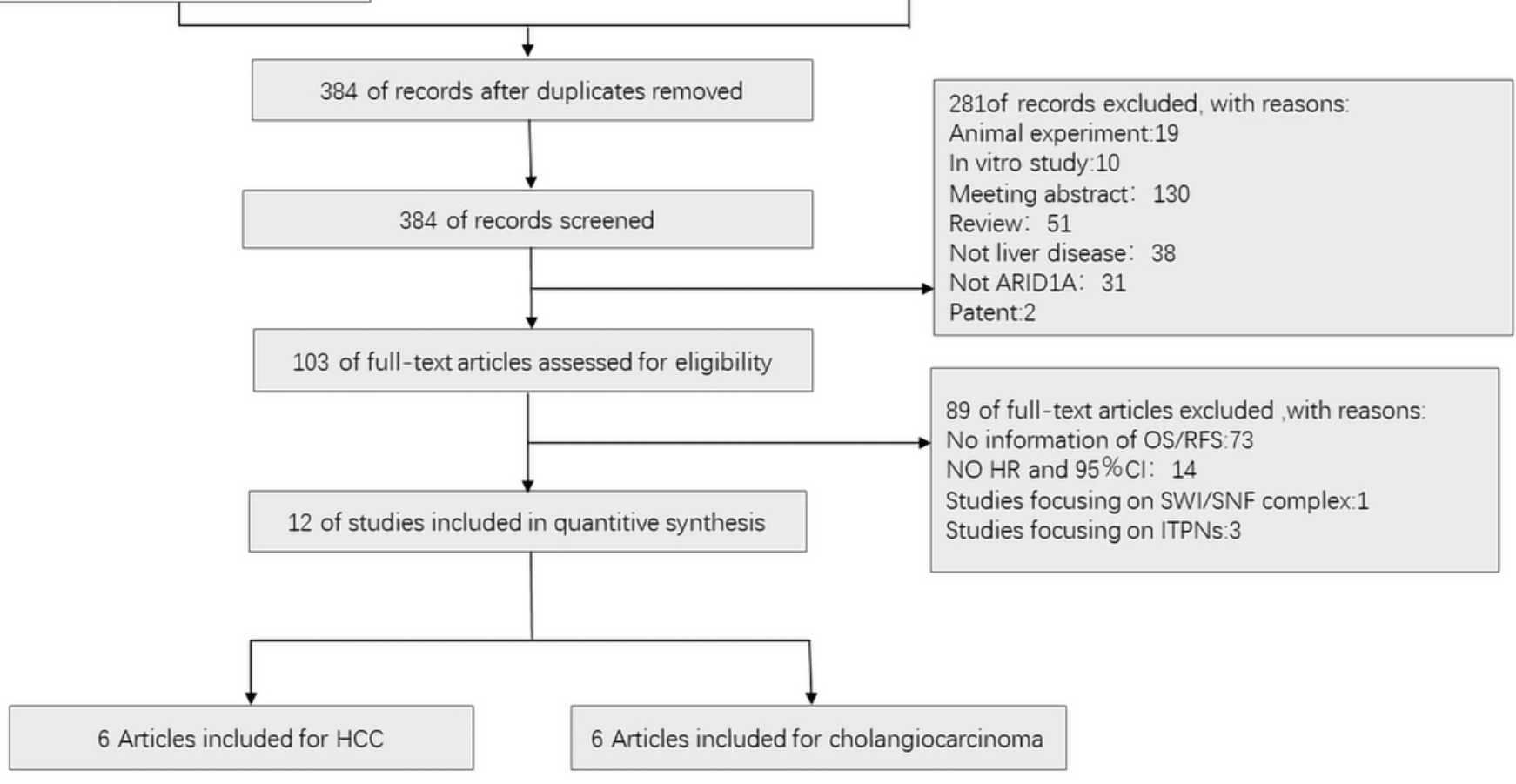

Figure 1

Flow chart of literature selection.

A

Author (year)

gene

Ruzzenente, A (2016)

Sasaki, Motoko (2016)

Simbolo, Michele (2018)

Wardell, Christopher (2018)

Subtotal (I-squared $=63.2 \%, p=0.043$ )

expression

Yang, S. Z (2016)

Yoshino, J (2020)

Subtotal $(I-$ squared $=0.0 \%, p=0.586$ )

Heterogeneity between groups: $p=0.517$

Overall (I-squared $=43.6 \%, p=0.115$ )

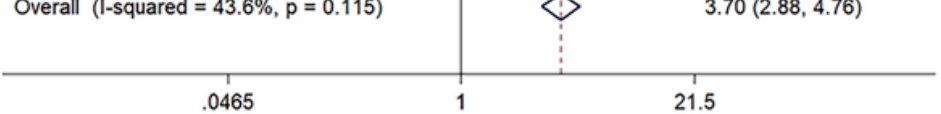

HR $(95 \% \mathrm{CI})$

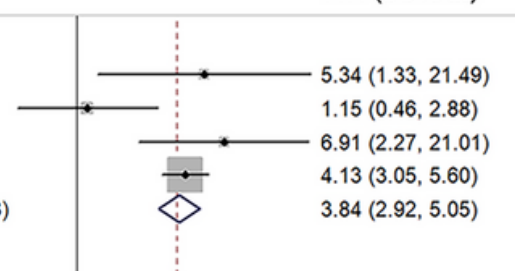

$3.97(1.30,12.12)$

$2.73(1.29,5.78)$

$3.07(1.65,5.71)$

$3.70(2.88,4.76)$

21.5

B

Author (year)

expression

Abe, Hiroyuki (2015)

He, Fei (2015)

Zhao, Jie (2016)

Zhou, Dingzhong (2019)

Subtotal $(\mathrm{I}$-squared $=63.6 \%, p=0.041$ )

gene

Kelly, L (2020)

Li, Li (2020)

Subtotal (I-squared $=0.0 \%, p=0.687$ )

Overall (I-squared $=61.0 \%, p=0.025$ )

NOTE: Weights are from random effects analysis

214
HR $(95 \% C I)$

$1.08(0.80,1.45)$

$2.12(1.14,3.94)$

$1.19(0.58,2.43)$

$2.31(1.36,3.92)$

$1.54(1.01,2.37)$

$2.12(1.01,4.43)$

$2.58(1.42,4.68)$

$2.39(1.50,3.79)$

$1.75(1.22,2.51)$

\section{Figure 2}

A, Forest plots of associations between ARID1A mutation or low expression and OS in cholangiocarcinoma; B, Forest plots of associations between ARID1A mutation or low expression and OS in HCC. 

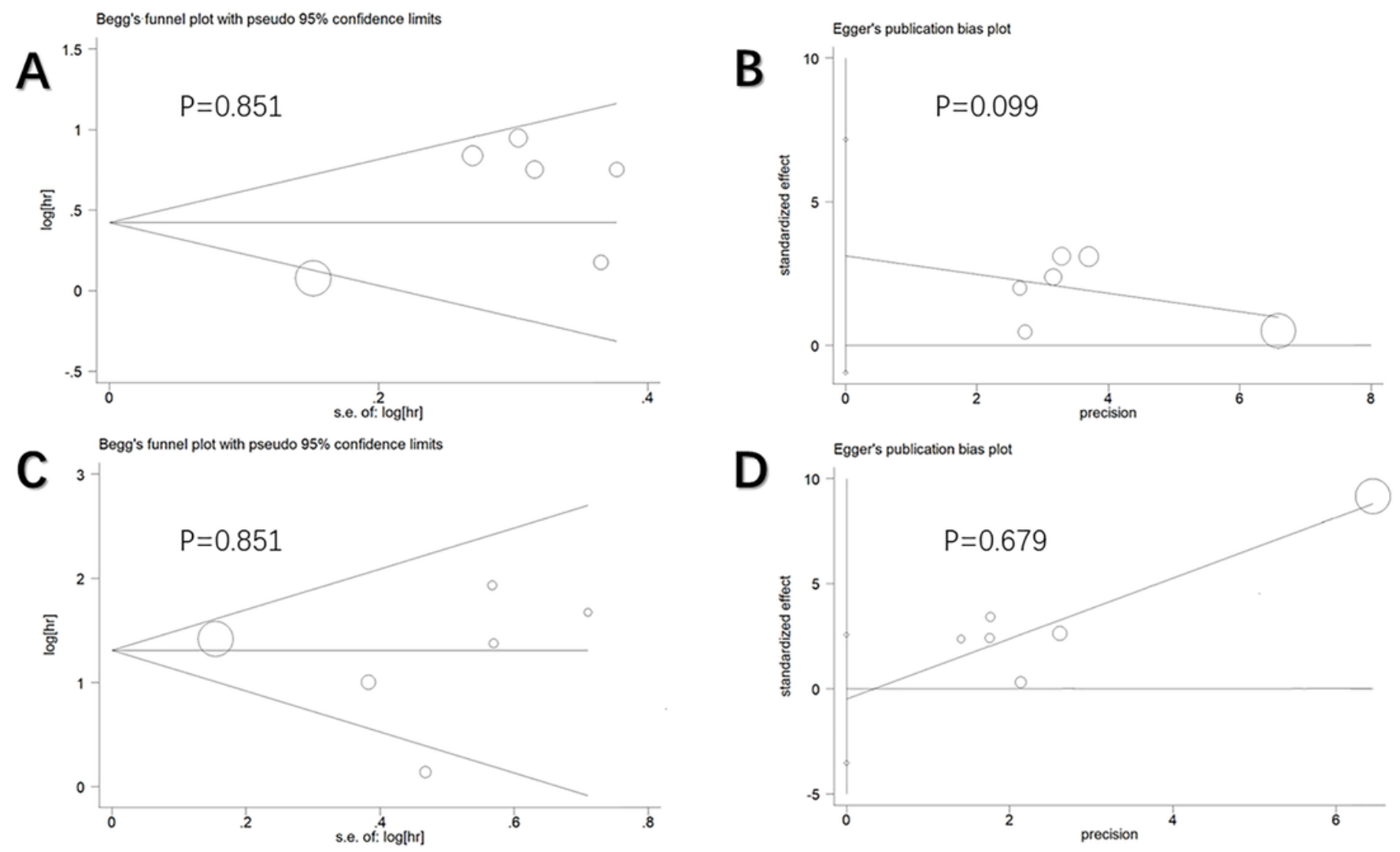

Figure 3

A, B: Publication bias analysis of HCC; C, D: Publication bias analysis of cholangiocarcinoma.

A

Figure 4

Sensitivity analysis of HCC studies and cholangiocarcinoma studies.

\section{Supplementary Files}

This is a list of supplementary files associated with this preprint. Click to download.

- Additionalfile1.docx

- Additionalfile2.png

- Additionalfile3.docx 